\title{
The trouble of sex Sex-determination, prenatal diagnosis and politics
}

\section{By Lisa Lindén ANd Helena Tinnerholm Ljungberg ${ }^{1}$}

\begin{abstract}
Recent decades have seen the rapid development of assisted reproductive technologies (ARTs) and methods of prenatal diagnosis. As a result, there are now several ways to predict the genetic sex of embryos as well as visualizing the sex of fetuses. However, how, when and where these technologies may be used have become politicized questions, both internationally and in Sweden. By providing a close reading of the Swedish political debate about technologies for the determination of the sex of fetuses and embryos from the end of the 1980s onwards, this article shows how technologies of prenatal diagnosis are articulated as problematic in the context of sex-determination. By "staying with the trouble" of sex in the political debate about sex-determination, we discuss how the ability to identify fetal or chromosomic sex through prenatal diagnosis is articulated as an unwanted trouble warranting political and ethical concern. The article also highlights the "ethico-political" restrictions imposed on information about the unborn's sex. It shows that, rather than prenatal diagnosis enabling promissory or hopeful visions of the future, the political debate is preoccupied with feelings of concern about the potential misuses of these technologies.
\end{abstract}

\section{KEYWORDS}

Prenatal diagnosis, political debate, sex-determination, technologies of trouble, ethico-politics, feelings of concern

Lisa Lindén holds a PhD in Technology and Social Change and is a postdoc at the Department of Sociology and Work Science, University of Gothenburg. She is interested in the politics of sex and public science. Her current research concerns gynecological cancer patient organizations.

Helena Tinnerholm Ljungberg holds a PhD in Political Science and is a Postdoctoral fellow at the Department of History of Science and Ideas, Uppsala University. Her research focuses on the politics of human reproduction and the institutionalization of research ethics in Sweden. 


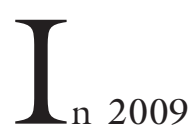

a heated public debate started when the media reported that a female patient in a Swedish hospital had requested an abortion, not just once but twice, immediately after she had found out the sex of the fetus. The debate centered around the fact that Swedish law gives women the right to an abortion until the end of the eighteenth week of the pregnancy while it is technically possible to determine the sex of the unborn $^{2}$ from the eleventh week (e.g. Wahlström 2009). A year earlier, in 2008, the right to an abortion had been extended to foreign women, after which it began to be realized that women were travelling from Denmark and Norway to Sweden to have abortions. Allegedly these women had been informed about the sex of their unborn and then decided to have an abortion in Sweden, where the laws were less restrictive (e.g. Ohlsson and Johannisson 2009). Concerned voices were raised in an effort to problematize sex as the sole reason for the desire to abort. More specifically, the debate circled around the possibility of restricting either the legitimate grounds for an abortion or the kinds of information pregnant women could receive after prenatal diagnosis.

Even though this debate was extensive, it was far from new. Both before and after the 2009 debate, the question of releasing information about the unborn's sex has been politicized as part of a broader discussion about the wide range of technologies now available for prenatal diagnosis. Ultrasonography, for example, reveals information about the fetus's visible external genitals, while other technologies provide information about its genetic or chromosomal characteristics, including its sex chromosomes. Examples of the latter include chorionic villus sampling (CVS), preimplantation genetic diagnosis (PGD) and non-invasive prenatal testing (NIPT). ${ }^{3}$ The use of prenatal diagnosis in Sweden is regulated by a law stating that pregnant women should be informed about the availability of prenatal diagnosis and that the decision over whether or not to use them is theirs to make (SFS 2006:351).4

As indicated by our account of the 2009 debate, the terrain of prenatal diagnosis and sex-information is rough and difficult to navigate, one in which political statements and ethical concerns become entangled with one another. Against this background, and focusing on the Swedish authorities' stance on the provision of sex-information, we aim to put insights from feminist Science and Technology Studies (STS) "to work" by analysing the Swedish political debate from the end of the 1980s onwards. We attend to how sex-determination - that is, the prediction of, for example, the unborn's sex through prenatal diagnosis - is introduced as an unwanted "trouble" into the political debate. We argue for the theoretical productivity of staying with this trouble as it allows us to attend to the complexities and ambiguities of this question (cf. Haraway 2016). The overarching question is: how is sex-determination (including sex-information) made into a trouble that needs to be managed and regulated?

Our aim is to stay with sex-determination as a trouble by analyzing how sex is articulated as a troubling incidental finding, how the provision of information to prospective parents about their unborn's sex is considered a problematic area, and how sex-determining technologies are permeated with feelings of anxiety, worry and concern. In particular, this focus enables us to discuss how the politics of sex includes and enacts feelings in contemporary technoscience. In doing so, we will discuss how sex-determining technologies relate to a vision of binary sex and how wanted and unwanted bodily differences, which often provoke affective arguments, are articulated in the context of sex-determination. 
The critical study of assisted reproductive technologies (ARTs), including prenatal diagnosis, sheds light on the entanglements of politics, ethics and technoscience. Studies have looked, notably, at ARTs in scientific and health care practice (Thompson 2005; Franklin and Roberts 2006), women's experiences of ARTs (Franklin 1997; Rapp 1999) and the visual culture of ARTs (Hartouni 1997). Of special relevance for our study are works analyzing how the body becomes sexed 5 through ARTs (Lie 2002; Thompson 2005). When it comes to sex-determination, this may seem a given. However, the point is that, due to political, social and technological complexities, how bodies, including fetuses, become sexed differs (Mitchell and Georges 1997; Rapp 1999). As we will show, how fetuses and embryos are articulated as sexed in the political debate over sex-determination is of interest for understanding the politics of technoscience generally, as well as, more particularly, in relation to its affective dimensions.

\section{PUTTING FEMINIST STS TO WORK}

While sex-determination through prenatal diagnostics is frequently discussed in the political debate in Sweden, it is often done implicitly or marginally. Making the implicit explicit, the marginal central, allows us to take seriously the importance of something that is rendered marginal in the wider debates our material forms part of. 6 This allows us to attend to how, why and for whom sex-determination is articulated as a trouble, and to attend closely to its ambiguities and complexities. As recent feminist STS work has shown, by "staying with" such trouble, it is possible to loosen "some of the tighter knots" (Roberts 2015, 31) that hold certain configurations of technoscience in place (e.g. Martin et al. 2015; Haraway 2016). To stay with the trouble thus allows us to examine carefully a marginal phenomenon that, at first sight, is eas- ily brushed aside or simplified. Therefore, for us, the notion of "trouble" serves as what Donna Haraway (2004, 335) defines as a "thinking technology", something to think with theoretically and methodologically. By staying with the trouble of sex-determination, we can analyze how, why and for whom it is presented as problematic.

As indicated by our account of the 2009 debate, sex-determination through prenatal diagnosis is an area where political navigations and responses are strongly connected to ethics. Concerns raised in this context are therefore simultaneously about both ethics and politics, entangling the two. Therefore, it is productive to approach sexdetermination as what Mariá Puig de la Bellacasa (2017) refers to as an ethico-political issue. Doing so, we attend carefully to how sex-determination is not simply about ethics, but simultaneously about politics. Drawing upon feminist STS sensibilities denoting politics and ethics as a matter of making worlds (e.g. Haraway 2004; Puig de la Bellacasa 2017), we emphasize that political debates about sex-determination participate in enacting particular, possible worlds. Indeed, and as Rayna Rapp (1999, 45 ) and Nete Schwennesen (2002, 48) have both noted, ethical reports, like the government reports we have analyzed, can be understood as "reproductive technologies" themselves, as they make specific worlds possible.

ARTs, such as technologies for prenatal diagnosis, are affective issues, and not only ethical and political ones. Others have analyzed the anxieties, hopes, enjoyment and pain connected with ARTs (Mitchell and Georges 1997; Rapp 1999; Adrian 2006). For example, by defining ARTs as "hope technologies" (Franklin 1997; Franklin and Roberts 2006), affective politics are highlighted. While acknowledging such insights, we have a partly different focus. Instead of concentrating on the affective dimensions of lay and health-care practices, we discuss how and when politicians' and 
policy-makers' arguments involve feelings. This is in line with Ettorre et al.'s call to feminist researchers on genomes to continue analyzing "the perceived seductiveness of particular technologies at particular moments of time and in particular locations" (2006, 139).

We acknowledge the increasing interest in feminist theory more generally (e.g. Pedwell and Whitehead 2012), and in feminist STS specifically (e.g. Martin et al. 2015; Roberts 2015), on the importance of feelings - or what others often call affects - in understanding ethics and politics. Drawing upon feminist STS work (Murphy 2015; Lindén 2016; Singleton and Mee 2017), we stress that feelings are enacted within stratified technoscientific worlds and that they are political and contextual. We explore how worry, concern and fear are entangled with sex-determination in the political debate, paying close attention to the ways in which feelings are entangled with ethico-politics, and showing how these issues, taken together, serve to articulate sexdetermination as a troublesome area.

A focus on feelings shows that, as a persistent trouble, sex-determination in the political debate seems to invoke what feminist STS scholar Celia Roberts (2015) defines as intense "feelings of concern". Roberts (2015) refers to Bruno Latour's (2004) notion of "matters of concern" in developing the notion of feelings of concern. As Puig de la Bellacasa (2017) argues, the phrase "matters of concern" denotes worries and thoughtfulness. Drawing upon Roberts (2015), we argue that the notion of "feelings of concern" productively strengthens the importance of feelings, thus helping us understand how, why and for whom sex-determination is presented as troublesome.

\section{THE STUDY AND EMPIRICAL MATERIAL}

The analysis presented in this article is based on a close reading of the discussions on sex-determination in relation to prenatal diagnoses in Swedish parliamentary debates and government documents. We take inspiration from feminist theory approaches to the practice of close reading that focus on the nuances and complexities of texts (Freeman 2010; Espinosa and Lukic 2012). Close readings are used in a variety of feminist frameworks, including deconstruction and affective readings. The method can be used to pay close attention to how texts are made up of specific, often unstable and ambiguous configurations, and how such configurations participate in making worlds. Moreover, close readings are a useful method for attending not only to the main articulations in a text, but also to those that it would be easy to dismiss as unimportant or marginal (Gallop 2000; Reardon et al. 2015). Since sex-determination often is a marginal matter in our material, this method is useful. Put differently, making use of close reading enables us to "stay with" the seemingly marginal matters that enact sex-determination as a trouble.

Selection of the empirical material was conducted by first mapping out the use of the concept "sex-determination" in the political debate. In a second step, we decided to focus on material from the end of the 1980s onwards because, in the mid-1980s, politicians from diverse political parties began to raise the question of the regulation of the use of prenatal diagnosis concerning, for example, the provision of sex-information (SoU 1984/85:4). The government initiated an official investigation, which resulted in two official reports: The pregnant woman and the fetus: two individuals (SOU 1989:51) and Genetics, integrity and ethics (SOU 2004:20). We analyze these, as well as the official documents and parliamentary debates that followed, including government bills, motions, committee memorials, chamber debates and reports from the Swedish National Council on Medical Ethics (hereafter referred to as SMER).

In the last decade, the political debate 
have increasingly focused on the question of genetic information, such as pre-implantation genetic diagnosis (PGD) and non-invasive prenatal testing (NIPT). No government report has been issued discussing these matters in recent years, but included in our empirical material are new governmental guidelines for prenatal diagnosis and PGD (SOSFS 2012:20), as well as a report on prenatal diagnosis that includes a discussion of NIPT (SMER 2011). All in all, our material consists of approximately 1,200 pages.

In the analysis, we have focused on the parts of the material where sex-determination is discussed. Due to the overall similarities in these discussions, we present our analysis thematically and not chronologically, divided into three different sections. These sections combine the main themes in our material with our theoretical approach, involving the ideas of sex as an incidental finding, technologies as trouble, and feelings of concern.

\section{SEX AS AN INCIDENTAL FINDING}

In the political debate, the sex of the fetus is most often discussed as information that is not sought after, the real purpose of prenatal diagnosis being to gather information for other medical purposes (SOU 2004:20, $65)$. For example, the official investigation from 1989 treats the sex of the fetus as an "incidental finding" (bifynd). Similarly, SMER writes:

[A] problem is that, in the case of both methods [ultrasound and PGD], examinations can generate "unwanted" incidental findings. The most common example being discussed is that ultrasound examinations and chromosome analysis can provide information about the fetus's sex. (SMER 2006, 8)

When sex-determination is debated in the political arena, the fetus's sex is seen as a concern because it is information not sought after, but produced only "incidentally" while investigating something else. The sex of the unborn becomes present as a persistent trouble that is "unwanted" and impossible to get rid of. Sex-determination as an incidental finding, however, is also contrasted with situations where information about the sex of the unborn is, as the material describes it, "medically justified" (in the case of "sex-specific" diagnoses such as haemophilia). Medically justified sex-determination is not only contrasted with sexdetermination for non-medical reasons, it is problematized considerably less.

In the material from the late 1980s, the Committee makes a distinction on ethical grounds between "general" and "selective" abortions. General abortion refers to a situation in which the woman does not want a child, whereas selective abortion refers to a situation where an abortion is performed due to fetal damage (e.g. SOU 1989:51, 12). In the committee's report, concern about the ethical implications of selective abortions is articulated as involving a:

(...) conflict between, on the one hand, human's equal worth regardless of health and ability to function and, on the other hand, the respect for the woman's (or the parents' as a couple) own judgment concerning what she (they) can cope with and handle. (SOU 1989:51, 12)

However, this distinction between general and selective abortion is not easily accepted in the debate that follows the report, as it is rejected by both SMER and the government. The government states that, for the woman or the family, the question is not about choosing or not choosing a certain individual, nor is it about physical functionality. For the woman, the government states, it is rather about not putting oneself in a situation that one does not feel able to handle (prop 1994/95:142, 32-34).

This debate is central to the 1990s debate about prenatal diagnosis. However, it 
also illustrates a difference between the ways in which sex on the one hand and medical health status on the other hand are depicted. While the government clarifies that, in the case of a "severely damaged or deformed child" (prop 1994/95:142, 34), it is important to support the woman's decision, regardless of her choice and it is made clear that the sex of the unborn is not in itself a legitimate ground for an abortion.

The distinction between decisions that are medically justified and those that are not articulates a further distinction between wanted and unwanted difference. While the fear of the use of sex-determination creating a future where sex differences are not appreciated finds expression, the fear of a future where differences related to health and disability are not appreciated is not as evident. Instead it is stated that an abortion decision made on the basis of information gained from prenatal diagnosis cannot be deemed "a hostile attitude towards disabilities” (prop. 1994/94:142, 33).

In the debate, fetuses and embryos are assumed to be sexed based on the observation of visible genitals (visualized through ultrasound) or the testing for sex chromosomes at different prenatal stages (through, e.g., PGD and NIPT). For example, one member of SMER argues that sex-determination transforms the embryo so that "it is no longer an 'it,' but a she or a he" (minority report in prop. 1994/95, 80), thus presenting sex as localized to certain parts of the human body, and as binary.

A fundamental point of departure in the political debate is that the mother and the unborn are separate (sexed) individuals with contrasting interests. For example, in the report The pregnant woman and the fetus - two individuals, it is written:

One sensitive question concerns how these incidental findings should be handled. We have previously stated that, through the development of prenatal diagnosis, the unborn has acquired an increasingly independent status in relation to the mother. Thus, the unborn can no longer be viewed as a part of the women's body, and consideration also needs to be given to the unborn's interests. (SOU 1989:51, 101)

The focus on the independent statuses of the woman and the unborn articulates what others call "fetal subjectivity" (Mitchell and Georges 1997) or "fetal personhood" (Franklin 1997). In their analysis of the use of ultrasound in Canada and Greece, Mitchell and Georges (1997) make the point that individuality is created through a focus on the fetus as a "baby" and not as a "fetus". In the case of sex-determination, this instead becomes a question of how prenatal diagnosis is assumed, incidentally, to make the fetus visible as a sexed subject ("he" or "she"), and not as an object without a sex ("it"). That is, the focus on the fetus as not an "it" but a "she" or a "he" is tied to a vision of binary sex as closely connected with individuality.

One government report, however, acknowledges some of the complexities involved in the determination of someone's sex. The report refers to eight different criteria for sex-determination:

[...] (i) sex chromosomes, (ii) patterns of sexhormones, (iii) gonads, i.e., testes or ovaries, (iv) internal sexual organs, (v) external genitals, (vi) secondary sexual characteristics, like hair growth, vocal pitch and distribution of body fat, (vii) the visual sex, such as it is assumed by others, and accordingly the role in which the person has been raised, (viii) the psychological gender identity, i.e., the person's own gender perception. (SOU 2004:20, 135)

This section is followed by the statement that in most cases these different criteria "do not cause any trouble" but that there exist "some for which the picture is not as clear" (SOU 2004, 135). In contrast to the 
overall political discussion, these eight criteria enable a more complex view of sex-determination. While these eight criteria are not a final solution for how to define someone's sex - it is certainly more complex than that - they point towards a less binary vision of sex difference.

As we have shown, in the political debate, sex-determination is articulated as a troubling incidental finding that comes about through a range of different ethicopolitical distinctions: between medical and non-medical justified sex-selection, between general and selective abortion, between the unborn and the mother as separate individuals, and between the unborn as an "it" and as a "she" or a "he". All of these separations identify sex-determination as a troublesome area.

\section{Technologies of TROUble}

In the political discussions surrounding prenatal diagnosis, an overarching concern is the risk of the wrongful use of information about the sex of the unborn. Wrongful use refers to a situation where information about the fetus's sex would result in an abortion (e.g. through ultrasound) or in the deliberate preselection of embryos (e.g. through PGD). The Committee of the Unborn Child considers the general use of fetal diagnosis for gathering medical information about the fetus and its health status to be ethically acceptable. However, in relation to sex-determination, the distinction already discussed between uses that are medically justified and those that are not is present. The report states that:

Foetal diagnosis should not, however, be permitted to be used for the purpose of determining the sex of the child if this is not - as in the case of haemophilia - medically motivated. (SOU 1989:51, 129, English in original)

Sex becomes most troublesome in instances where it is not medically relevant. When sex-determination is medically justified, it is viewed as ethically acceptable; when it is not, it becomes a troublesome area. For example, while SMER states that it is ethically acceptable to use genetic information to diagnose diseases that are inherited with the $\mathrm{X}$-chromosome, the same information is viewed as problematic in relation to fetalDNA (NIPT) analysis due to the potential non-medical uses of sex information. They write:

If sex-determination should be part of a family planning strategy, the question becomes ethically controversial. If an abortion is justified with the argument that the fetus has the "wrong sex", this could be questioned from an ethical perspective, since sex is not a disease and should hardly be a reason for abortion. (SMER 2011, 20)

Throughout, sex-determination seems to be considered the most problematic when it is connected to the possibility of sex-selection, either through abortion (on the basis of sex) or preselecting embryos based on information about sex rather than on medical grounds. Thus, sex-information as such is not articulated as a trouble. Instead, the potential practices that might follow from this knowledge are what are troublesome and need managing.

It is frequently emphasized that nonmedically justified information about the sex of a fetus or embryo should only be given to the woman being examined if she requests it (e.g. prop. 1994/95:142, 26$27)$. If she does not want the information, the treating physician should actively inform the woman about matters that could be relevant to the unborn's health, but not about its sex. This proposed solution to restrict but not ban sex-information has become the dominant solution and has been repeated in subsequent political debates since.

Throughout, values of self-determina- 
tion and human integrity are referred to as reasons for the women's (or prospective parents') right to obtain information about the unborn's sex if it is requested. SMER $(2004,25)$ refers to "the right to self-determination" in arguing that "[i]nformation about the fetus's sex should [...] not be automatically provided, but if it is requested it must be issued". By invoking the idea of self-determination it is assumed that it is not possible to prohibit women from receiving information about the sex of the fetus.

The focus on self-determination is repeatedly combined with the idea that a woman is competent to make a good choice based on the information she is given. For instance, a government bill from 1994 states that "[w]e consider the pregnant woman to be fully competent to handle all information, and this includes information about the fetus's sex" (prop, 1994/95:142). Here, the woman is considered capable of making the "right" choice, yet the idea that she should only be given information about the sex of the unborn's sex if she requests it assumes that she knows that she can receive this information.

The choice to decide to have an abortion based only on information about the unborn's sex is mentioned several times as ethically unacceptable or as incompatible with prevailing western understandings of human dignity. For example, SMER confronts sex-information with a western equality discourse, stating that it is "difficult to combine the use of prenatal diagnosis for the mere purposes of deciding the fetus's sex with the equal values ascribed to men and women in our western tradition" (prop. 1994/95:142, appendix 2, 68). The Swedish Medical Research Council argues along the same lines: sex-determination, if not medically justified, "constitutes a factual impingement on human dignity and it is therefore ethically objectionable" (prop. 1994/95:142, appendix 4, 81).
Read in light of the focus on non-medically justified sex-determination as ethically unacceptable, the idea that the woman is capable of making the "right" choice can be understood as her being capable of making the decision not to have an abortion based on information about the sex of the unborn. Nonetheless, the decision to withhold sex-information if the woman does not request it reveals a lingering concern that some women or prospective parents might choose wrongly. Thus, a tension is present between what is perceived to be the right choice and the possible troubling misuse of the technology that arises from the idea that self-determination and human integrity are essential values in Swedish society.

\section{FEELINGS OF CONCERN}

In the debate, technologies of prenatal diagnosis are discussed in terms of both technological and social development and of the possibilities that are enabled by their "fast" and "explosive" development. In the government report from 1989, for instance, it is stressed that "the rapid development" (SOU 1989:51, 24) of ARTs creates new possibilities for sex-determination. Technological development is most often articulated as a problem. For example, concerning PGD, the government report from 1989 expresses a concern that the "development has gone too far before society has gained information about these matters and is able to regulate these activities" (SOU 1989:51, 111). There is thus a worry that PGD is too efficient and that it may be driven too far. The fear is that this may be one step towards an undesirable future in which all possible unwanted qualities have already been deselected at the pre-embryo stage. SMER writes: "The selective characteristics of the PGD method, in combination with the commercialization of reproduction, raises concerns". They mention sex preselection as one existing option, and write 
that "soon other characteristics may also be possible to predict" $(2004,19)$.

The unpredictability of the future uses of prenatal diagnosis is articulated as worrying. There is a fear that the development is happening too quickly and that it will not be possible to control it. Thus, a dystopic vision of a future that does not accept and appreciate difference is envisioned. Such fears are explicit in the official report $G e^{-}$ netics, Integrity and Ethics, where they discuss the report The pregnant woman and the fetus - two individuals:

There is simply a fear that women/parents will deselect some fetuses in preference to others and about where a development of this kind might lead. The inquiry's view of prenatal diagnosis may be said to have been characterized by such a fear (...). (SOU 2004:20, 267)

Stating that the investigation and the official report were both characterized by a fear that women or prospective parents would decide to "choose some fetuses in preference to others", the committee implicitly refers to sex preselection.

In both official reports, words such as "hesitation", "carefulness" and "ethical watchfulness" are used, something which, together with articulations of fear and worry, serve to present prenatal diagnosis and sex as an ethico-political issue permeated with what Roberts (2015) regards as intense feelings of concern.

Feelings of concern are also present when members of the Christian Democrats and the Social Democrats discuss the possibilities for sex-determination through prenatal diagnosis (mot. 1994/95:So28; protocol 2005/06:111; mot. 2005/06:So530; mot.1994/95:So497). In a minority report to the government report $(2004: 20,384)$, one Christian Democrat member writes that "the micro eugenic aspects of PGD worries me", since "today, for example, it is possible to choose [a fetus or embryo] based on sex". Other members write that technologies of prenatal diagnosis are "worrying," even "alarming," since they are used in a "completely instrumental" manner. This is discussed as an example of how "the phenomenon of reproduction is becoming more and more technologized" and how "the integrity of early human life risks being completely abolished" (minority report in SOU 2004:20, 385). Moreover, one member calls this a "slippery slope", since the development of ARTs has happened too quickly to be controllable. Here, prenatal diagnosis is articulated as dangerous since it may bring about a highly unwanted future.

The feelings of concern articulated by the Christian Democrats (and in the motion by members of the Social Democrats mentioned above) are similar to the dominant stand one finds in the political debate. However, unlike the others, they argue that a prohibition is needed on providing information about the sex of the unborn to the pregnant woman. This is necessary, it is stated, since some might misuse prenatal diagnosis for their own benefit, and not for the good of the unborn.

Since it is emphasized that such misuse is extremely rare, the majority of women who do not misuse sex-information are implicitly contrasted with the minority who may use the information wrongly. As discussed in the last section, this distinction between a woman's right to choose and possibly problematic decisions is a general thread in the debate. However, this distinction becomes particularly evident in relation to some of the politician's focus on ARTs as so worrying that a ban on providing information about the sex of the unborn is necessary.

We have shown that prenatal diagnosis is presented as worrying and that technological developments are articulated through feelings of concern about the possible future uses of these technologies. Thus, the political debate does not involve a story about scientific progress and suc- 
cess, but rather it is dominated by voices arguing for the need to be cautious and hesitant regarding the use of these technologies.

\section{Concluding DISCUSSION}

In this article, we have analyzed how sexdetermination is made into a trouble that needs managing. We have examined how the sex of the unborn is articulated as, most often, an unwanted, incidental finding, how technologies for sex-determination are articulated as a problem, since some people may misuse them, and how the politics of sex-determination are permeated with feelings of concern.

As we have discussed, the trouble of sex is presented as a question of whether information about the unborn's sex should be provided to the pregnant woman or prospective parents. The predominant solution is articulated through a formulation stating that, if the woman or prospective parents request it, information about the unborn's sex should be provided. This formulation contains an implicit idea that the woman or prospective parents have the right to decide on the basis of the values of self-determination and human integrity. However, this puts these values in tension with the recurring statement that it is unethical to abort a fetus or deselect an embryo based on sex-information alone. This serves to draw a boundary between those decisions that are deemed to be good and others that are problematic. This in its turn is related to the present fear of a development towards a society that does not appreciate (binary) sex differences. Yet, the selection of embryos or fetuses based on whether or not they show a disability is assumed to be less problematic. In this sense, yet another trouble emerges: when boundaries are drawn between what is ethically justifiable and what is not, an ethico-political boundary is also drawn between wanted and unwanted difference.
We have shown how prenatal diagnosis in a context of sex-determination is articulated as a troublesome area. While one could expect at least part of the debate on sex-determination to be formed by enthusiasm and optimism over the possibilities enabled by prenatal diagnosis, this focus is to a large extent absent. Our study highlights ARTs as technologies of trouble and concern rather than, as most feminist STS studies have emphasized, technologies of promise, hope and/or enjoyment (see e.g. Franklin 1997; Thompson 2005).

The focus on technologies of concern and trouble sheds empirical light on the recent feminist STS critique of the tendency in feminist theory to imagine positive or happy feelings as opening up for, or affirming, a more promising world (Murphy 2015; Lindén 2016; Singleton and Mee 2017). As these scholars argue, the politics of diverse feelings need to be taken seriously. This is especially the case in our study, as the political debate about sex-determination is dominated by voices arguing that we should be hesitant and cautious in respect to ARTs. This suggests that the political implications of such feelings (e.g. concern, worry and fear) need to be attended to.

Our study demonstrates how closely feelings are related to ethico-political concerns. Politics and ethics are entangled in the debate we have analyzed: the political decision to restrict sex-information to situations where the woman or the prospective parents request it is closely linked to what is perceived as ethically justifiable, and that, in its turn, is presented as preserving the values of self-determination, gender equality and human integrity. Moreover, the solution to restrict sex-information is to a high degree connected to concerns, fears and worries about the potential misuse of the technologies. Taken together, this clearly illustrates the ethico-politics of feelings in technoscience.

Diverse feelings can be understood as involving ethico-politics in a range of empiri- 
cal areas (e.g. Puig de la Bellacasa 2017). Thus, we would not argue that feelings as an ethico-political issue are limited to concern, worry or fear, nor to the context of sex-determination. Rather, based on our study, we argue that an important aspect of the ethico-politics of feelings in technoscience is to stay with the trouble of how diverse feelings are evoked, managed and mobilized to pursue political arguments.

While some instances in the analyzed political debate show how feelings of fear and concern can be used to pursue problematic or conservative political standpoints (such as visions of binary sex, technological developments as inherently worrying or the integrity of early human life as essential), other instances are less straightforward. Based on our results, we emphasize the need to take seriously the complexity of all feelings, not least given the potential social implications of technoscientific politics. Importantly, how ARTs, whether technologies of enjoyment and hope, or technologies of trouble and concern, are managed, regulated and debated, matters for the worlds we are yet to live in.

\section{Notes}

1. The research conducted for this article was supported by the Swedish Research Council [Dnr 446- 2014-1749].

2. Following Lupton (2013), we use the wording "the unborn" instead of, for example, "the unborn child". As Lupton $(2013,6)$ argues, "the terminology that is adopted to refer to the products of human conception is inevitable politically, culturally and emotionally charged". As Lupton shows, if we would refer to fetuses or embryos as unborn babies or children, we would assume that such entities are already infants and persons. Similarly, we use the wording "prospective parents" instead of parents or parents-to-be, this to not presume that the existence of a fetus or embryo positions people as parents of those entities, or that they automatically will become parents in the future.

3. Ultrasonography is a common prenatal techno- logy that uses sound waves to make the fetus visible on a monitor. It gives information about how the pregnancy is proceeding. Amniocentesis is a test of the amniotic fluid, where cells from the fetus can be detected and tested. Chorionic villus sampling (CVS) involves collecting a piece of the placenta that is then tested. NIPT is a relatively new procedure that collects and tests fetal cells in a blood sample from the pregnant woman. PGD entails screening fertilized eggs during IVF treatment and before they are implanted. The social outlook on gender selection in, for example, the USA seems to be under transformation, from a practice that virtually everyone distances themselves from to one that has gained at least some acceptance (Ettorre et al. 2006; Bhatia 2010). This change could partly be explained with reference to a differentiation between the first and second generation of sex-preselection methods (Bahtia 2010). Whereas the first generation allowed abortions of fetuses on the basis that they were perceived to be the "wrong" sex, the second generation involved selecting embryos or sperm with the "right" sex (ibid.). For an overview of feminist perspectives on sex selection, see Burrell 2005.

4. PGD is regulated by Swedish law and may not be used to select embryos based on any specific predicted attributes. It may only be used to make sure that the embryo does not carry any serious genetic disease inherited from the prospective parents. Only in rare cases (and if permitted by the National Board of Health and Welfare) can PGD be used to select embryos that are potential donors of stem cells to a severely ill sibling (SFS 2006:351).

5. We follow other feminist scholars in using the word "sex" instead of "gender" in this article (e.g. Roberts 2014). Highlighting the impossibility of separating a social gender from physical sex, these scholars show that an "additional" term connoting the social dimension easily reproduces a problematic separation between gender and sex.

6. Previous research on sex-determination in political debates in Sweden is scarce. One exception is the political scientist Lenita Freidenvall's analysis of the history of abortion in Sweden showing how, in the beginning of the 1990s, politicians linked arguments against sex selection to "a Christian and human rights perspective" (2005:133). In the international context, however, scholars have studied policies and debates surrounding the issues of selective abortions, prenatal diagnosis and PGD in relation to sex-determination (Scott 2007; Bhatia 2010; Karpin and Savell 2012). 


\section{REFERENCES}

- Adrian, S. 2006. Nye skabelsesberetninger om ag, sed og embryoner: et etnografisk studie af skabelser på sedbanker og fertilitetsklinikker. Doctoral dissertation, Linköping: Linköping University.

- Bhatia, R. 2010. Constructing gender from the inside out: sex selection practices in the United States. Feminist Studies. 36(2), 260-291.

- Burrell, R. 2005. Feminist views on sex selection. In: Jónsdóttir, I. ed. PGD and embryo selection: Report from an international conference on preimplantation genetic diagnosis and embryo selection. TemaNord 2005:591. Nordic Council of Ministers, Copenhagen.

- Espinosa Sánchez, A., and Luki, J. 2012. Feminist perspectives on close reading. In: Buikema, R., Griffin, G., and Lykke, N. eds. Theories and methodologies in postgraduate feminist research. New York: Routledge.

. Ettorre, E., Rothman, B. K., and Steinberg, D. L. 2006. Feminism confronts the genome: introduction. New Genetics and Society. 25(2), 133-142. - Franklin, S. 1997. Embodied progress: a cultural account of assisted conception. London: Routledge. - Franklin, S. and Roberts, C. 2006. Born and made: an ethnography of preimplantation genetic diagnosis. Princeton: Princeton University Press. . Freeman, E. (2010). Time binds: queer temporalities, queer histories. Durham: Duke University Press.

- Freidenvall L. 2015. In pursuit of bodily integrity in Sweden. In: Outshoorn J. ed. European women's movements and body politics: citizenship, gender and diversity. London: Palgrave Macmillan. . Gallop, J. 2000. The ethics of reading: close encounters. Journal of Curriculum Theorizing.

16(3), 7-17.

- Haraway, D. 2004. Cyborgs, coyotes, and dogs: a kinship of feminist figurations and there are always more things going on than you thought! Methodologies as thinking technologies. In: Haraway, D. ed. The Haraway Reader. New York and London: Routledge.

- Haraway, D. 2016. Staying with the trouble: making kin in the Chthulucene. Durham: Duke University Press.

- Hartouni, V. 1997. Cultural conceptions: on reproductive technologies and the remaking of life.

Minneapolis: University of Minnesota Press.

- Karpin, I. and Savell, K. 2012. Perfecting pregnancy: law, disability, and the future of reproduction. Cambridge: Cambridge University Press.

- Latour, B. 2004. Why has critique run out of steam? From matters of fact to matters of concern. Critical Inquiry. 30(2), 225-248.
- Lie, M. 2002. Science as father? Sex and gender in the age of reproductive technologies. European Journal of Women's Studies. 9(4), 381-399.

- Lindén, L. 2016. Communicating care: the contradictions of HPV vaccination campaigns. Lund: Arkiv förlag.

- Lupton, D. 2013. The social worlds of the unborn. Basingstoke, Hampshire: Palgrave Macmillan. - Martin, A., Myers, N., and Viseu, A. 2015. The politics of care in technoscience. Social Studies of Science. 45(5), 625-641.

- Mitchell, L. and Georges, E. 1997. Cross-cultural cyborgs: Greek and Canadian women's discourses on fetal ultrasound. Feminist Studies. 23(2), 373-401.

- Mot. 1994/95:So28 med anledning av prop. 1994/95:142 Fosterdiagnostik och abort av Alf

Svensson m.fl. (kds).

- Mot. 2005/06:So530 Aborter av Torsten Lindström m.fl. (kd).

- Mot. 1994/95:So497 Fosterdiagnostik av Margareta Israelsson m.fl. (s).

- Murphy, M. 2015. Unsettling care: troubling transnational itineraries of care in feminist health practices. Social Studies of Science. 45(5), 717-737. - Ohlsson, K. and Johannisson, E. 2009. Varning för abort på grund av kön. Svenska Dagbladet. February 29 [accessed 7 January 2018]. Available from: www.svd.se/varning-om-abort-pa-grund-av-kon. - Pedwell, C., and Whitehead, A. 2012. Affecting feminism: questions of feeling in feminist theory. Feminist Theory. 13(2), 115-129.

- Proposition 1994/95:142. Fosterdiagnostik och abort.

- Protocol 2005/06:111.

- Puig de la Bellacasa, M. 2017. Matters of care: speculative ethics in more than human worlds. Minneapolis: University of Minnesota Press.

- Rapp, R. 1999. Testing women, testing the fetus: the social impact of amniocentesis in America. New York: Routledge.

- Reardon, J., Metcalf, J., Kenney, M. and Barad, K. 2015. Science \& justice: the trouble and the promise. Catalyst: Feminism, Theory, Technoscience. l(1), 1-48.

- Roberts, C. 2014. The entanglement of sexed bodies and pharmaceuticals: a feminist analysis of early onset puberty and puberty-blocking medications. Subjectivity. 7(4), 321-341.

- Roberts, C. 2015. Puberty in crisis: the sociology of early sexual development. Cambridge: Cambridge University Press.

- Schwennesen, N. 2002. Nye reproduktionsteknologier: offer eller medaktør? Kvinder, Køn es Forskning. 3, 47-56. 
- Scott, R. 2007. Choosing between possible lives: law and ethics of prenatal and preimplantation genetic diagnosis. Oxford: Hart Publishing.

- SFS 2006:351. Lag om genetisk integritet m.m. - Singleton, V., and Mee, S. 2017. Critical compassion: affect, discretion and policy-care relations. The Sociological Review Monographs. 65(2), 130149.

- SOSFS 2012:20 (M). Fosterdiagnostik och preimplantorisk genetisk diagnostik.

- SoU 1984/85:4. Om vissa medicinsk-etiska frågor.

- SoU 1989:51. Den gravida kvinnan och fostret två individer. Om fosterdiagnostik. Om sena aborter.

- SoU 2004:20. Genetik, integritet och etik.
- Statens medicinsk-etiska råd (SMER). 2011. Fosterdiagnostik: Etisk analys för diagnostik med foster-DNA (dnr 38/11).

- Statens medicinsk-etiska råd (SMER). 2004.

Skrivelse om preimplantatorisk genetisk diagnostik.

- Statens medicinsk-etiska råd (SMER). 2006. Yttrande om etiska frågor kring fosterdiagnostik.

- Thompson, C. 2005. Making parents: the ontological choreography of reproductive technologies. Cambridge, MA: MIT Press.

- Wahlström, Jan. 2009. Föräldrar ska inte kunna välja kön på sina barn. Göteborgsposten. February 29 [Accessed 7 January 2018]. Available from: www.gp.se/nyheter/debatt/föräldrar-ska-intekunna-välja-kön-1.1065161. 


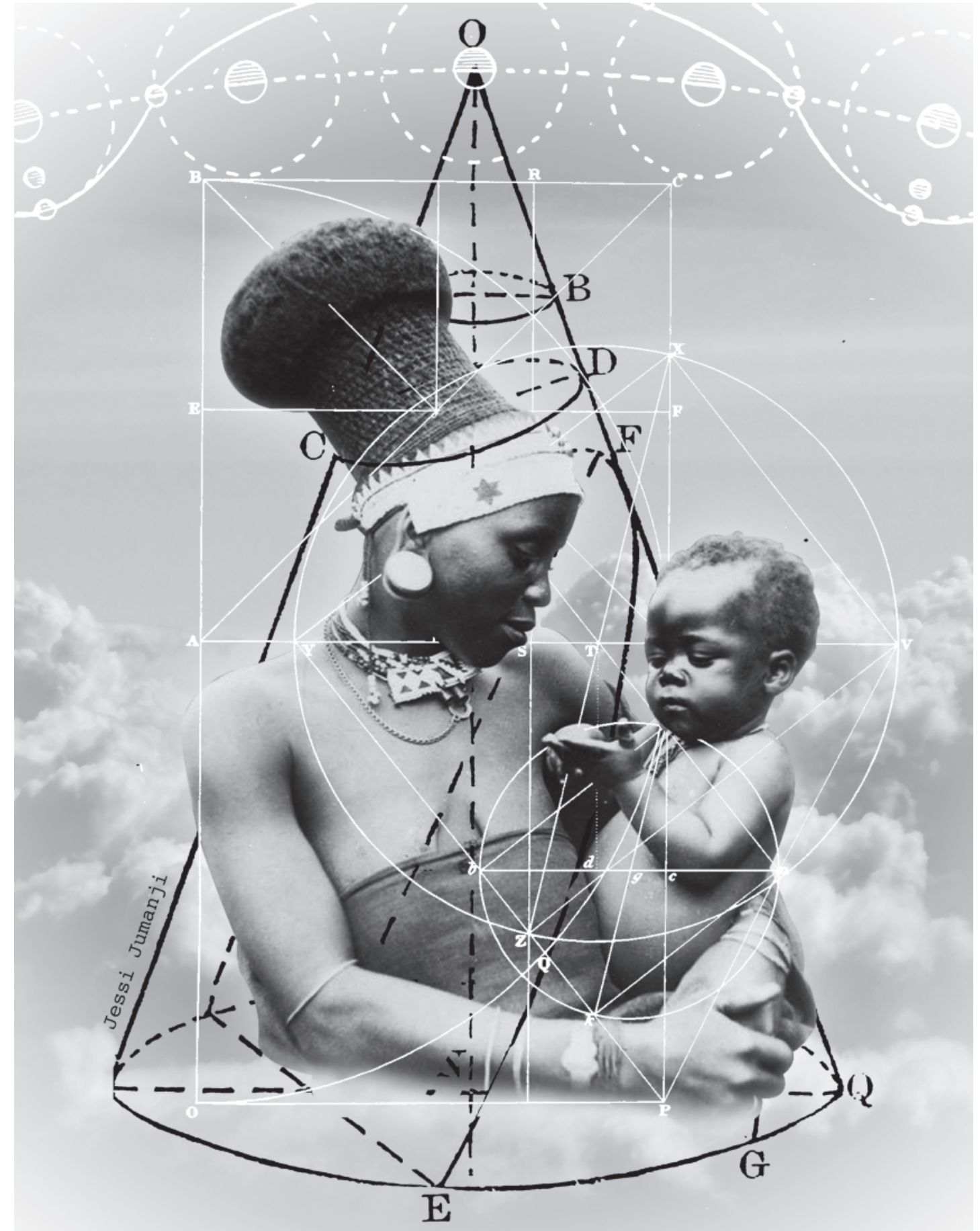

Jessi Jumanji “Maathematics2". Collage Serie: Maathematics 